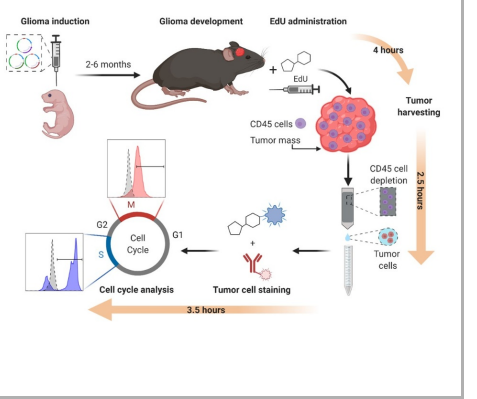

MAY 15, 2020

\section{open $\mathcal{O}$ Access}

\section{DOI:}

dx.doi.org/10.17504/protocol s.io.bf8hjrt6

\section{Document Citation: Maria} B Garcia Fabiani, Padma Kadiyala, Pedro R.

Lowenstein, Maria G. Castro 2020. An optimized protocol for in vivo analysis of tumor cell division in a Sleeping Beauty-mediated mouse glioma model.. protocols.io https://dx.doi.org/10.17504/p rotocols.io.bf8hjrt6

License: This is an open access document distributed under the terms of the Creative Commons Attribution License, which permits unrestricted use, distribution, and reproduction in any medium, provided the original author and source are credited

Created: May 11, 2020

Last Modified: May 15, 2020

DOCUMENT integer ID: 36841

Keywords: Glioma, cell cycle, EdU

\section{(3) An optimized protocol for in vivo analysis of tumor cell division in a Sleeping Beauty-mediated mouse glioma model.}
Maria B Garcia
Padma
Fabiani $^{1}$,
Kadiyala $^{1}$,
Pedro R.

Maria G. Castro ${ }^{1}$

1University of Michigan - Ann Arbor<smiles>C1CCCCCCCC1</smiles>

Maria B Garcia Fabiani

\section{ATTACHMENTS \\ STARProtocols_5-11- \\ 20_iProtocol.pdf}

\section{ATTACHMENTS}

\section{STARProtoco \\ Is_5-11- \\ 20 iProtocol. \\ pdf}

\section{ATTACHMENTS}




\title{
An optimized protocol for in vivo analysis of tumor cell division in a Sleeping Beauty-mediated mouse glioma model
}

\author{
Maria B. Garcia-Fabiani ${ }^{1,2,3,{ }^{*}, \text { Padma Kadiyala }}{ }^{1,2}$, Pedro R. Lowenstein ${ }^{1,2}$ and Maria G. Castro ${ }^{1,2,4,{ }^{* \star}}$ \\ Department of Neurosurgery, University of Michigan Medical School, Ann Arbor, MI, 48109, USA. \\ Department of Cell and Developmental Biology, University of Michigan Medical School, Ann Arbor, MI, 48109, USA. \\ Technical contact. \\ Lead contact. \\ *Correspondence: mgarciaf@umich.edu(M.B.G.F.); \\ ${ }^{\star *}$ Correspondence: mariacas@med.umich.edu(M.G.C.)
}

\section{SUMMARY}

Malignant gliomas are the most common and aggressive primary brain tumor in adults, and high mitotic rates are associated with gliomas' malignancy. Gliomas were modelled in mice using the Sleeping Beauty system, to encode genetic lesions recapitulating the human disease. The presented workflow allows the study of glioma cells' proliferation in vivo, enabling the identification of different phases of the cell cycle, with the advantage that EdU staining does not involve denaturation steps and samples do not require histological processing.

For complete details on the use and execution of this protocol, please refer to Núñez FJ et al. (2019).

\section{BEFORE YOU BEGIN}

In vivo profiling of glioma cells' cell cycle analysis is performed in a genetically engineered glioma model in mice utilizing the Sleeping Beauty (SB) transposon system (Wiesner et al., 2009, Calinescu et al., 2015, Koschmann et al., 2016, Nunez et al., 2019, Garcia-Fabiani et al., 2020, Comba et al., 2020). To achieve this, plasmids encoding the different genetic alterations of interest, which will be stably inserted into the genome of mouse brain cells, need to be constructed. Those sequences encoding for genetic alterations, i.e. the transposons, are flanked by inverted repeats/directed repeats (IR/DR) that will be recognized by the SB transposase. This enzyme will integrate these transposons into the genome in a "cut and paste" manner (Calinescu et al., 2015). One advantage of this method is that the expression of these genes is coupled to the expression of fluorescent proteins, so that when gliomas develop, tumors can be recognized under a stereo-zoom microscope equipped with a fluorescent light (Figure $1 \mathrm{~A}$ ). These plasmids are co-injected along with a plasmid encoding for the SB transposase. This 
plasmid also contains the coding sequence for the Luciferase enzyme flanked by IR/DR, which will get inserted into the host genome as well (Figure $1 \mathrm{~A}$ ). This enables the study of plasmid uptake and tumor growth by bioluminescence. Refer to (Wiesner et al., 2009, Calinescu et al., 2015)for a detailed cloning protocol of SBcompatible plasmids (i.e. pKT-IRES-Katushka). Depending on the type of genetic alterations introduced, tumors will develop and animals will reach the humane endpoint within 2 to 6 months after the SB procedure (Calinescu et al., 2015, Koschmann et al., 2016, Nunez et al., 2019, Comba et al., 2020)(Table 1). Invivo EdU staining is performed when the tumor is large, i.e., when bioluminescence reaches a signal of $10^{6} \mathrm{photons} / \mathrm{s} / \mathrm{cm}^{2} / \mathrm{sr}$, but before the tumor burden endpoint.

\section{Breeding cage set up}

\section{Timing: 20-30 days}

1- Set up a breeding cage three to four weeks before the planned date for SB-injections.

2- Once pregnancy is confirmed, place the male mouse in a separate cage and monitor the female daily until pups are born.

3- At post-natal day 1, proceed with the SB protocol.

\section{Plasmid preparation for SB procedure}

\section{Timing: 1 hour}

Prepare the plasmid DNA mix with the in vivo transfection reagent (in vivo Jet-PEI), which will be injected into the lateral ventricle of 1 day-old mouse pups.

CRITICAL: The quality of the DNA to be injected is critical. DNA solutions must be sterile, endotoxin free and highly concentrated for a small volume injection. Up to five plasmids can be injected per DNA/JetPEI mix.

1- DNA mix: add $2.8 \mu \mathrm{g}$ of the plasmid encoding $\quad$ the SB transposase (pT2/SB100x-Luc) and $5.75 \mu \mathrm{g}$ of each plasmid encoding for the transposons. Add $10 \mu \mathrm{l}$ of $10 \%$ glucose and sterile water up to $20 \quad \mu$ l. 2-In vivo Jet-PEI mix: the amount of transfection reagent depends on the amount of total DNA used and it can be calculated using the following formula:

$\mu \mathrm{L}$ of in vivo jet-PEI $=[(\mu \mathrm{g}$ DNA $\times 3) \times \mathrm{N} / \mathrm{P}$ ratio $] / 150$,

where N/P is the optimal ratio of nitrogen residues in the polyethyleneimine (PEI) to the phosphate residues in the DNA, 3 the number of nanomoles of anionic phosphate in $1 \mu \mathrm{g}$ of nucleic acid, and $150(\mathrm{mM})$ the concentration of nitrogen residues in the in vivo jet-PEI solution. The optimal N/P factor for in vivo transfections is usually 7.

Add $10 \mu \mathrm{l}$ of $10 \%$ glucose and sterile water up to $20 \mu \mathrm{l}$.

3- Combine both mixes by pipetting. Vortex the mixture briefly, spin down and incubate it at $25^{\circ} \mathrm{C}$ for 20 minutes.

4- Prepare the stereotaxic frame to be used to perform the intraventricular injections

a.Place the $10 \mu \mathrm{L}$ syringe with a $30 \mathrm{G}$ hypodermic needle into the micropump. Make sure that the injection system is working properly by withdrawing and releasing $10 \mu$ of water.

b.Cool down the stereotactic neonatal stage to $2-8{ }^{\circ} \mathrm{C}$ with a slurry of dry ice placed in alcohol. 


\section{Injection of SB-based plasmids into the lateral ventricle of neonatal mice to generate glioma in situ.}

\section{Timing: 1-1.30 hours}

This workflow for inducing brain tumors in neonatal day 1 pups has been adopted from (Wiesner et al., 2009) and is extensively used in our group to develop low or high grade glioma models harboring different genotypes (Calinescu et al., 2015, Koschmann et al., 2016, Nunez et al., 2019, Garcia-Fabiani et al., 2020, Comba et al., 2020). Brain tumors are induced by transposon-mediated integration of genetic alterations delivered in plasmid DNA into the host genome, without the need of viral vectors (Figure 1, A \& B) (Table 1). The tumors arise from the glial cells next to the ependymal layer of the lateral ventricle, where plasmids are injected (Koschmann et al., 2016, Nunez et al., 2019). Gliomas generated with the SB-based method recapitulate salient features of the human disease (Calinescu et al., 2015, Koschmann et al., 2016, Nunez et al., 2019), thus representing a versatile and reliable model to study brain tumor's biology and the efficacy of therapeutic agents.

\section{1- Load the syringe with $10 \mu$ of the DNA/JetPEI solution.}

2-Induce anesthesia by hypothermia by placing the mouse pup wrapped in a gauze on wet ice for 2 minutes. 3- Place the pup on the previously cooled stereotaxic stage and immobilize the head using the ear bars. Wipe the head with ethanol $70 \%$.

CRITICAL: Make sure that the head is placed firmly and parallel to the stereotaxic stage.

4- Adjust the microdrive screws to lower the needle close to the head and place it in the midline intersection of the parietal and occipital bones (lambda).

5- Adjust the stereotaxic coordinates to $0.8 \mathrm{~mm}$ lateral and $1.5 \mathrm{~mm}$ rostral to the lambda (Figure 1, C).

6- Lower the needle until it touches the skin, record the dorso-ventral coordinates.

7- Lower the needle $1.5 \mathrm{~mm}$ to pierce the skin and skull. At this position, the tip of the needle should be inside the lateral ventricle (Figure 1, C).

8- Using an automatic injector, inject $0.75 \mu \mathrm{l}$ of the DNA/JetPEI solution at a rate of $0.5 \mu \mathrm{l} / \mathrm{min}$.

9- After the DNA/JetPEl solution has been injected, keep the pup in the frame for 1 minute.

CRITICAL: To prevent burns, make sure that the temperature of the frame does not go below $2{ }^{\circ} \mathrm{C}$.

10-Anesthetize the next pup by repeating step 2.

11-Slowly and gently lift the needle to pull it out from the brain.

12-Place the pup under a heating lamp until normal breathing resumes, monitoring that it recovers its mobility and its rosy color. Apply a gentle lung massage if necessary to aid the breathing recovery.

CRITICAL: Limit the time between mouse anesthesia and the post-injection warm up. This will ensure the pup will survive better after the SB plasmid injection. Mouse survival is usually absolute when this procedure lasts less than 10 minutes. If the procedure lasts more than 10 minutes, mouse survival could be reduced by $10 \%$. 
13-Once the pup is breathing and moving normally, place it back in the cage with the mother and monitor the mother's response to the pups.

CRITICAL: If there are more pups in the breeding cage, mark the tail of the injected animal before putting it back in the cage to avoid injecting the same pup twice.

14-After all the injections are done, monitor the cage for another 30 minutes to ensure that the mother is nurturing the pups.

CRITICAL: Usually, mothers instantly accept the pups after the procedure. However, if it is observed that the mom is not nurturing the pups, a surrogate mother can be added to the cage.

15-Place cage back to the animal room and monitor tumor growth.

CRITICAL: The pT2/SB100x-Luc not only encodes for the SB transposase, but also for the Luciferase enzyme, which gets inserted into the host genome. Thus, plasmid uptake by brain cells can be monitored 24 hours after the intraventricular injection using an IVIS bioluminescence imager (Figure 1, D, first panel) (Calinescu et al., 2015, Koschmann et al., 2016, Nunez et al., 2019, Garcia-Fabiani et al., 2020). Monitoring tumor growth by bioluminescence as the animals grow might be challenging because of the increased optical density of the fur, skin and skull. However, when the tumor reaches a threshold size, 1-2 $\mathrm{mm}^{3}$ for darkly pigmented C57BL6 mice, tumor detection is possible (Figure 1, D, second and third panels).

\section{Tumor monitoring by bioluminescence imaging and EdU administration}

\section{Timing: 1-4 hours}

Depending on the genetic alterations introduced into the mouse brain cells, animals will display tumor burden symptoms in two or more months after the SB procedure (Table 1). These symptoms consist of weight loss, ruffled fur, hunched posture, impaired mobility or other abnormalities in movement. Usually, tumor progression can be monitored by bioluminescence two or three weeks before signs of tumor burden become evident. Endpoint tumors commonly display a bioluminescence of $10^{7}-10^{8}$ photons $/ \mathrm{s} / \mathrm{cm}^{2} / \mathrm{sr}$ (Figure 1, D). EdU injections should be performed before mice show signs of tumor burden; when tumor is easily detectable by bioluminescence but is not yet necrotic or hemorrhagic. For this procedure, EdU is injected when animals display $10^{6}$ photons $/ \mathrm{s} / \mathrm{cm}^{2} / \mathrm{sr}$ IVIS signal (Figure 1, D).

1. Measure tumor volume using an IVIS bioluminescence imager.

2. Anesthetize the animals in the anesthesia chamber with oxygen/isoflurane flow (1.5-2.5\% isoflurane).

3. Inject $100 \mu \mathrm{l}$ of Luciferin solution $(30 \mathrm{mg} / \mathrm{ml}) \quad$ intraperitoneally and start a timer for 5 minutes.

4. Place the animal back to the chamber and wait for 3-4 min.

5. Start oxygen/isoflurane flow in the bioluminescence chamber and place the animal in the slot equipped with the glass nose cones. 
6. Place the animal in the bioluminescence chamber and when the timer goes off acquire a series of 6 images, at 2 minutes' intervals with an automatic exposure time, median binning and an open aperture of $f=1$.

7. Select the area of interest (i.e. the head) with an oval figure and measure the luminescence intensity using the calibrated unit photons $/ \mathrm{s} / \mathrm{cm}^{2} / \mathrm{sr}$.

8. If the animal has a $10^{6}$ photons $/ \mathrm{s} / \mathrm{cm}^{2} / \mathrm{sr}$ signal, proceed to EdU administration.

9. EdU injection

a.Inject $10 \mathrm{mg} / \mathrm{kg}$ of the EdU dilution intraperitoneally. For instance, for mice weighting $30 \mathrm{~g}$, inject $300 \mu \mathrm{l}$ of the EdU dilution.

b.Wait 3 hours and proceed with the next steps.

\section{Tumor dissection and depletion of CD45 cells}

\section{Timing: 2,5 hours}

CRITICAL: For the next steps, work quickly, always keep the cells cold, and use pre-cooled solutions. This will prevent cell death, capping of antibodies on the cell surface and non-specific cell labeling.

1- Three hours after EdU injection, euthanize the animal with an overdose of isoflurane. Examine animal responsiveness by toe and tail pinch.

2- Decapitate the animal's head and gently dissect the brain from the skull.

3- Place the brain into a Petri-dish on wet ice. Since the SB-plasmids encoding for the oncogenes also encode for fluorescent proteins (Figure 1, A), tumor tissue can be visualized and accurately dissected from the brain using a stereo-zoom microscope equipped with a fluorescent light illumination system (Figure 2, A).

4- Dissect the tumor from the brain using scalpels.

5- Place the tumor pieces into a $50 \mathrm{ml}$ conical tube with $5 \mathrm{ml}$ of NS complete media.

6- Using a cell strainer on a $50 \mathrm{ml}$ conical tube and the sterile pestle of a $1 \mathrm{ml}$ syringe, disaggregate the tumor tissue. Rinse the strainer with $10 \mathrm{ml}$ of NS media through the strainer. Continue homogenizing the tissue through the strainer. Rinse two more times with $10 \mathrm{ml}$ of NS media. Keep the single cell suspension on ice (Figure 2, B).

7- Centrifuge the cells at $300 \mathrm{xg}$ for 5 minutes at $25^{\circ} \mathrm{C}$.

8- Remove supernatant and add $1 \mathrm{ml}$ of $1 \mathrm{X}$ cold RBCLB. Incubate 1 minute on ice. To stop cell lysis, add $9 \mathrm{ml}$ of DPBS.

9- Centrifuge the cells at $300 \mathrm{xg}$ for 5 minutes at $25^{\circ} \mathrm{C}$.

10- Discard supernatant and resuspend the pellet in $90 \mu \mathrm{l}$ of cold BSA-EDTA buffer.

11- Count the cells using trypan blue and a hemocytometer.

12- Add $10 \mu$ of CD45 MicroBeads per $10^{7}$ total cells. Mix well by pipetting.

CRITICAL: When working with $10^{7}$ or less cells, follow the volume of reagents listed above. When working with higher amount of cells, scale up all reagent volumes accordingly.

13- Incubate beads-cell suspension for 15 minutes at $4{ }^{\circ} \mathrm{C}$.

CRITICAL: Do not incubate on ice, as it might require longer incubation time.

14- Add $1 \mathrm{ml}$ of BSA-EDTA buffer to wash the cells and centrifuge at $300 \mathrm{xg}$ for 10 minutes at $4{ }^{\circ} \mathrm{C}$. 
15- Discard the supernatant and resuspend up to $10^{8}$ cells in $500 \mu \mathrm{l}$ of coldBSA-EDTA buffer.

16- Place the LS column on a suitable MACS separator.

CRITICAL: LS columns allow the retention of up to $1 \times 10^{8}$ labelled cells and processing samples with up to $2 \times 10^{9}$ cells. There are different column size options available and we recommend evaluating which is the one that best suits the tissue to be used and the approximate amount of cells to be analyzed.

17- Precondition the LS column by rinsing it with $3 \mathrm{ml}$ of BSA-EDTA buffer and letting all the solution to go through it.

18- Place a $15 \mathrm{ml}$ collection tube below the column and add the pre-separation filter on top of it.

CAUTION: Pre-separation filters on the top of the columns are important to prevent cell clumping and column clogging.

19- Apply the cell suspension onto the filter and collect the CD45- cells that pass through the column (Figure 2, C).

20- Once the suspension stops dripping, wash the column once with $3 \mathrm{ml}$ of cold BSA-EDTA buffer, collecting the eluate in the same tube (first eluate).

21- To further deplete CD45+ cells from this suspension, pass this first eluate through a second pre-conditioned column placed in the magnetic field, with a pre-separator filter on the top. Collect the eluted cells.

22- When the entire cell suspension has gone through the column, apply $3 \mathrm{ml}$ of cold BSA-EDTA buffer to rinse it, collecting the eluted cells (second eluate). These cells are mostly tumor cells, depleted of immune cells.

23- Pellet the CD45-depleted tumor cells by centrifuging the second eluate at $300 \mathrm{xg}$ for 10 minutes at $4{ }^{\circ} \mathrm{C}$.

Note: This method allows the separation of tumor cells from immune cells with a substantial amount of viable cells. The number of CD45+ cells in the tumor enriched cell fraction is negligible (Garcia-Fabiani et al., 2020).

Flow staining: Click-iT reaction and phospho-Ser10-histone 3 intracellular staining

\section{Timing: 2,5 hours.}

EdU is a thymidine analog that is incorporated into DNA during active DNA synthesis. The detection of EdU is based on a click reaction between a picolyl azide, which is coupled to a fluorescent dye, and an alkyne (EdU nucleoside). In this protocol, we used a Pacific Blue-coupled azide. Moreover, the phosphorylation of the serine residue 10 in the histone 3 tail $(p-S e r 10-H 3)$ is a critical event in mitosis. Histone-3-Serine-10 phosphorylation is important for chromosome condensation, and starts at late $\mathrm{G} 2$ phase, peaks at metaphase and decreases from late anaphase to early telophase (Kim et al., 2017). To study cell cycle characteristics, we performed EdU and pSer10-H3 intracellular staining on tumor cells.

Note: It is highly recommended to use single stained compensation controls and single stained samples as controls, i.e., "EdU only" and "p-Ser10-H3 only" samples. Also, keep unstained cells for compensation set up. 24- Add $3 \mathrm{ml}$ of $1 \% B S A-P B S$ buffer to wash the cells and centrifuge at $300 \mathrm{xg}$ for 5 minutes at $4{ }^{\circ} \mathrm{C}$. Remove supernatant.

25- For $10^{6}$ cells, add $100 \mu$ l of Click-iT fixative (Component $\mathrm{D}$ ) and mix well by pipetting.

26- Incubate the samples in fixative for 15 minutes at $25^{\circ} \mathrm{C}$, protected from light.

27- Add $3 \mathrm{ml}$ of $1 \%$ BSA-PBS buffer to wash the cells and centrifuge at $300 \mathrm{xg}$ for 5 minutes at $4{ }^{\circ} \mathrm{C}$. Remove 
supernatant.

28- Resuspend the pellets in $100 \mu \mathrm{l}$ of $1 \mathrm{X}$ Click-iT permeabilization and wash reagent. Mix well.

29- Incubate the samples 15 minutes at $25^{\circ} \mathrm{C}$.

30- Add $1 \mu \mathrm{l}$ of p-Ser10-H3-PE antibody resuspended in $100 \mu \mathrm{l}$ X Click-iT permeabilization and wash reagent to each sample.

31- Incubate the samples for 30 minutes at $25^{\circ} \mathrm{C}$, protected from light.

32 - Add $3 \mathrm{ml}$ of $1 \% \mathrm{BSA}$-PBS buffer to wash the cells and centrifuge at $300 \mathrm{xg}$ for 5 minutes at $4{ }^{\circ} \mathrm{C}$. Remove supernatant.

33-Add $100 \mu$ of $1 X$ Click-iT permeabilization and wash reagent. Mix well.

34- Prepare Click-iT EdU buffer additive 1X: dilute Click-iT EdU buffer additive 10X 1:10 in deionized water. For each reaction $50 \mu$ of Click-iT EdU buffer additive $1 \mathrm{X}$ are necessary.

For each reaction, prepare the following cocktail:

\begin{tabular}{|l|l|}
\hline COMPONENT & $\begin{array}{l}\text { VOLUME FOR 1 REACTION } \\
(\mu \mathrm{l})\end{array}$ \\
\hline PBS, D-PBS or TBS & 438 \\
\hline $\begin{array}{l}\text { Copper protectant } \\
\text { (Component F) }\end{array}$ & 10 \\
\hline $\begin{array}{l}\text { Fluorescent dye picolyl } \\
\text { azide }\end{array}$ & 2.5 \\
\hline $\begin{array}{l}\text { Click-iT EdU buffer additive } \\
\text { 1X }\end{array}$ & 50 \\
\hline TOTAL & 500.5 \\
\hline
\end{tabular}

Note: Use the Click-iT cocktail within 15 minutes of preparation.

35- Add $500 \mu$ l of the Click-iT cocktail to each sample with the fixed cells and mix well. At this point, the total volume is $600 \mu$ l.

36- Incubate the reaction for 30 minutes at $25^{\circ} \mathrm{C}$, protected from light.

37- Add $3 \mathrm{ml}$ of $1 \mathrm{X}$ Click-iT permeabilization and wash reagent to wash the cells and centrifuge at $300 \mathrm{xg}$ for 5 minutes at $4{ }^{\circ} \mathrm{C}$. Remove supernatant.

38- Resuspend cells in flow buffer and analyze.

Pause Point: Once the cells are fixed, data acquisition by flow cytometry can be performed the next day. Store stained cells at $4^{\circ} \mathrm{C}$ protected from light.

\section{Data acquisition}

\section{Timing: 1-2 hours.}

39- Use the single stained samples and the unstained sample to perform laser compensation. Once the laser set up is done, proceed to run the samples.

40- Gating strategy: perform doublet discrimination by gating first in a SSC-W vs SSC-H plot and then FSC-W vs FSC$\mathrm{H}$ plot (Figure 3A).

41- To identify EdU positive cells, plot single cells as a histogram to analyze the distribution of the dye (i.e., Pacific 
Blue) (Figure 3A, lower left panel). To identify p-Ser10-H3 positive cells, we plotted the cells on a separate histogram and measured PE staining (Figure 3A, lower right panel).

42- Run the single stained controls and set the gates.

43- Run samples, collecting at least 30,000 events.

44- Analyze data using FlowJo software.

\section{EXPECTED OUTCOMES}

In general, proliferating cells going through $S$ phase of the cell cycle incorporate EdU while DNA is being synthetized. After the Click-iT reaction, cells in the S phase will be positive for the fluorochrome bound to the azide and the cell population of interest can be easily detected by flow cytometry. After EdU incorporation and Click-iT reaction, two peaks in the stain's histogram can be identified: one peak with low or no staining, i.e. cells not undergoing $S$ phase; and a second peak with positive staining levels, i.e. cells undergoing $S$ phase (Figure 3A, lower left panel).

To identify cells going through mitosis, p-Ser10-H3 intracellular staining was performed. The analysis can be done in the same way as the EdU analysis. Cells going through mitosis will be stained with anti-p-Ser10-H3 antibody (Prigent and Dimitrov, 2003, Li et al., 2005, Nunez et al., 2019). These cells can be easily detected as a single positive peak in the histogram, whereas cells that are unstained for the marker constitute the negative population of cells, i.e. not undergoing mitosis (Figure $3 \mathrm{~A}$, lower right panel).

The genetic background of the glioma induced by the SB method will define the aggressiveness of the tumor and will have an impact on the cell cycle characteristics and on the proportion of tumor cells undergoing $S$ and $M$ phases (Figure 3B).

\section{LIMITATIONS}

- Tumor bearing mice displaying an IVIS signal of $10^{8}-10^{9}$ photons $/ \mathrm{s} / \mathrm{cm}^{2} / \mathrm{sr}$ will be negative for EdU and $\mathrm{p}$-Ser10H3 staining. This IVIS signal usually corresponds to maximum tumor burden. At this stage glioma cells are not proliferative and tumor tissue starts to become necrotic. Cells should only be harvested during an exponential growth stage to accurately characterize cell cycle profiles.

- Animals bearing tumors that display IVIS signal of $10^{4}-10^{5}$ photons $/ \mathrm{s} / \mathrm{cm}^{2} / \mathrm{sr}$ are not suitable for EdU and $\mathrm{p}$ Ser10-H3 staining. At this IVIS signal the tumor is still very small. In this case, not enough tumor cells can be acquired from a single animal for flow cytometry analysis.

- In order to draw accurate conclusions about the tumor cell cycle profile, tumor cells could be stained with additional cell surface markers such as CD133 or CD44 (Brown et al., 2017). In the case of SB-derived gliomas, tumor cells could also be identified by staining for the fluorescent reporter proteins associated to the expression of the oncogenes introduced.

- CD45+ cell depletion method reliably depletes immune cells from the tumor homogenate (Garcia-Fabiani et al., 2020). In case these reagents cannot be acquired, immune cells could be discriminated from the glioma cells during flow cytometry by staining the tumor cell suspension with an anti-CD45 antibody coupled to a fluorochrome. Right after tumor dissociation, wash the samples with flow buffer and stain $1 \times 10^{6}$ cells in $200 \mu$ of flow buffer with $1 \mu \mathrm{l}$ of anti-CD45 antibody fluorochrome-conjugated. Incubate for 30 minutes on ice, protected 
from light. Wash twice with flow buffer and continue with cell fixation, p-Ser10-H3 intracellular staining and ClickiT reaction. EdU and p-Ser10-H3 positive cells should then be identified within the CD45-negative population.

- We were not able to perform this method on orthotropic implantable brain tumor model. We believe that this could be related to different properties of SB-based tumors versus implanted tumors regarding the penetration of the EdU compound.

\section{TROUBLESHOOTING}

\section{Problem}

Low or no EdU labelling.

\section{Potential Solution}

The time elapsed between EdU administration and animal euthanasia should be determined empirically and it could vary amongst the type of tumor being harvested and its anatomic location.

\section{Problem}

Non-specific/high fluorescent staining of p-Ser10-H3.

\section{Potential Solution}

To minimize non-specific p-Ser10-H3 staining, blocking CD16/CD32 antibody could be utilized. This reagent contains immunoglobulins that will bind to the Fc-receptor, thereby blocking the non-specific binding of $p$ Ser10H3 to other receptors on the tumor cell. Also, adding and additional washing step after the incubation of the sample with the antibody might be added to further eliminate unspecific binding.

\section{Problem}

No p-Ser10-H3 staining.

\section{Potential Solution}

The concentration of $\mathrm{p}$-Ser10-H3 antibody should be determined empirically. Antibody titration could be performed in fixed and permeabilized cells.

Intracellular proteins may be lost if excessive cell permeabilization occurred before sufficient cross-linking is attained. This could be the case if methanol is used as a fixative instead of formaldehyde.

\section{Problem}

Cellular clumping during flow cytometry

\section{Potential Solution}


Vortex the sample gently at low speed before running the sample.

Clumps can also be removed by filtering the sample through a $70 \mu \mathrm{m}$ nylon mesh before running it in the flow cytometer.

\section{Problem}

High side scatter signal

\section{Potential Solution}

This could be due to lysed or broken cells. Ensure that samples are fresh and prepared according to the workflow detailed above. Do not vortex cells at a high speed before data acquisition.

\section{RESOURCE AVAILABILITY \\ Lead Contact}

Further information and requests for resources and reagents should be directed to and will be fulfilled by the Lead Contact, Maria G. Castro, mariacas@med.umich.edu.

\section{Materials Availability}

Catalog numbers for the available plasmids used to generate the genetically engineered mouse glioma models using the Sleeping Beauty method are detailed in Table 1. Those plasmids that are not currently available in Addgene will be provided by the Lead Contact upon request with no restrictions.

\section{Data and Code Availability}

No datasets or code were generated during this study.

\section{ACKNOWLEDGMENTS}

This work was supported by NIH/NINDS Grants, R37-NS094804, R01-NS105556 and 1R21NS107894 to M.G.C.; NIH/NINDS Grants R01-NS076991, and R01-NS096756 to P.R.L.; the Department of Neurosurgery, the Rogel Cancer Center, Program in Cancer Hematopoiesis and Immunology $(\mathrm{CHI})$, the ChadTough Foundation, Pediatric Brain Tumor Foundation, and Leah's Happy Hearts to M.G.C. and P.R.L.; RNA Biomedicine Grant F046166, Forbes Foundation Grant, University of Michigan Medical School, Rogel Cancer Center Scholar, University of Michigan Medical School to M.G.C. and American Brain Tumor Association Basic Research Fellowship "in Memory of Bruce and Brian Jackson" to M.B.G.F.

\section{AUTHOR CONTRIBUTIONS}

M.G.C and P.R.L conceived the research question and provided funding; M.B.G.F and P.K. performed the experiments, M.B.G.F. prepared the figures, M.B.G.F and P.K. wrote the manuscript under the supervision of M.G.C. and P.R.L. All authors read and edited the final version of this manuscript.

\section{DECLARATION OF INTERESTS}

The authors declare no competing interests. 


\section{REFERENCES}

BROWN, D. V., FILIZ, G., DANIEL, P. M., HOLLANDE, F., DWORKIN, S., AMIRIDIS, S., KOUNTOURI, N., NG, W., MOROKOFF, A. P. \& MANTAMADIOTIS, T. 2017. Expression of cd133 and cd44 in glioblastoma stem cells correlates with cell proliferation, phenotype stability and intra-tumor heterogeneity. PloS one,12.

CALINESCU, A. A., NUNEZ, F. J., KOSCHMANN, C., KOLB, B. L., LOWENSTEIN, P. R. \& CASTRO, M. G. 2015.

Transposon mediated integration of plasmid DNA into the subventricular zone of neonatal mice to generate novel models of glioblastoma. Journal of visualized experiments : JoVE.

COMBA, A., DUNN, P. J., ARGENTO, A. E., KADIYALA, P., VENTOSA, M., PATEL, P., ZAMLER, D. B., NÚÑEZ, F. J., ZHAO, L., CASTRO, M. G. \& LOWENSTEIN, P. R. 2020. Fyn tyrosine kinase, a downstream target of receptor tyrosine kinases, modulates antiglioma immune responses. Neuro-oncology.

GARCIA-FABIANI, M. B., COMBA, A., KADIYALA, P., HAASE, S., NÚÑEZ, F. J., ALTSHULER, D., LOWENSTEIN, P. R. \& CASTRO, M. G. 2020. Isolation and characterization of immune cells from the tumor microenvironment of genetically engineered pediatric high-grade glioma models using the sleeping beauty transposon system. Methods in enzymology. Elsevier.

KIM, J.-Y., JEONG, H. S., CHUNG, T., KIM, M., LEE, J. H., JUNG, W. H. \& KOO, J. S. 2017. The value of phosphohistone h3 as a proliferation marker for evaluating invasive breast cancers: A comparative study with ki67. Oncotarget, 8, 65064.

KOSCHMANN, C., CALINESCU, A. A., NUNEZ, F. J., MACKAY, A., FAZAL-SALOM, J., THOMAS, D., MENDEZ, F., KAMRAN, N., DZAMAN, M., MULPURI, L., KRASINKIEWICZ, J., DOHERTY, R., LEMONS, R., BROSNAN-CASHMAN, J. A., LI, Y., ROH, S., ZHAO, L., APPELMAN, H., FERGUSON, D., GORBUNOVA, V., MEEKER, A., JONES, C., LOWENSTEIN, P. R. \& CASTRO, M. G. 2016. Atrx loss promotes tumor growth and impairs nonhomologous end joining DNA repair in glioma. Science translational medicine, 8,328ra328.

LI, D. W., QIN, Y., CHEN, J. T., HAO, Z., LIU, R. M. \& HUANG, X. T. 2005. Dynamic distribution of ser-10 phosphorylated histone h3 in cytoplasm of mcf-7 and cho cells during mitosis. Cell research,15, 120-126.

NUNEZ, F. J., MENDEZ, F. M., KADIYALA, P., ALGHAMRI, M. S., SAVELIEFF, M. G., GARCIA-FABIANI, M. B., HAASE, S., KOSCHMANN, C., CALINESCU, A. A., KAMRAN, N., SAXENA, M., PATEL, R., CARNEY, S., GUO, M. Z., EDWARDS, M., LJUNGMAN, M., QIN, T., SARTOR, M. A., TAGETT, R., VENNETI, S., BROSNAN-CASHMAN, J., MEEKER, A., GORBUNOVA, V., ZHAO, L., KREMER, D. M., ZHANG, L., LYSSIOTIS, C. A., JONES, L., HERTING, C. J., ROSS, J. L., HAMBARDZUMYAN, D., HERVEY-JUMPER, S., FIGUEROA, M. E., LOWENSTEIN, P. R. \& CASTRO, M. G. 2019. Idh1$\mathrm{r} 132 \mathrm{~h}$ acts as a tumor suppressor in glioma via epigenetic up-regulation of the DNA damage response. Science translational medicine, 11.

PRIGENT, C. \& DIMITROV, S. 2003. Phosphorylation of serine 10 in histone h3, what for? Journal of cell science, 116, 3677-3685.

WIESNER, S. M., DECKER, S. A., LARSON, J. D., ERICSON, K., FORSTER, C., GALLARDO, J. L., LONG, C., DEMOREST, Z. L., ZAMORA, E. A., LOW, W. C., SANTACRUZ, K., LARGAESPADA, D. A. \& OHLFEST, J. R. 2009. De novo induction of genetically engineered brain tumors in mice using plasmid DNA. Cancer research, 69,431-439.

\section{FIGURE LEGENDS}

Figure 1. Sleeping beauty transposase method to model glioma in mice. A)Generic plasmid maps used to generate gliomas in mice using the SB transposase method. GFP and Katushka are green and red fluorescent proteins, respectively. miR-30 sequences flank a shRNA encoding sequence designed to silence specific genes. The DNA transposons to be inserted are flanked by inverted repeats/direct repeats (IR/DR), which are recognized by the 
transposase. B) These sequences are then randomly integrated into the host genomic DNA sites, between bases $T$ and A. C) Schematic of a 1 day-old mouse pup, showing the coordinates for plasmid injection into the lateral ventricle, at $1.5 \mathrm{~mm}$ rostral and $0.8 \mathrm{~mm}$ lateral to the lambda and $1.50 \mathrm{~mm}$ ventral. D) From left to right:

bioluminescence scanning of a mouse pup 1 day after SB plasmid injection, when a large tumor has developed $\left(10^{6}\right.$ photons $\left./ \mathrm{s} / \mathrm{cm}^{2} / \mathrm{sr}\right)$ and at tumor burden endpoint $\left(10^{7}\right.$ photons $\left./ \mathrm{s} / \mathrm{cm}^{2} / \mathrm{sr}\right)$.

Figure 2. Images depicting critical steps of tumor dissection and CD45+ cell depletion procedure. A) Images showing a mouse SB-generated glioma under a stereo-zoom microscope equipped with a fluorescent light illumination system. In this example, the tumor was generated with SB plasmids encoding for genes coupled to GFP (middle picture) and Katushka (right picture) expression as reporter genes. Scale bars: $0.5 \mathrm{~cm} \mathrm{~B}$ ) Image showing a $50 \mathrm{ml}$ conical tube, with a cell strainer on the top and a pestle, used to disintegrate the tumor tissue. C) Image illustrating MACS CD45-depletion column set up.

Figure 3. Flow cytometry gating strategy used to identify EdU+ and p-Ser10-H3+ glioma cells.A) Total cells are gated to exclude cellular debris (top left plot). Then, doublet discrimination gating is performed to filter out cellular aggregates (top middle and right plots). Lower panel: Left histogram: glioma cells positive for EdU (black=unstained control, blue=EdU (Pacific Blue staining)). Right histogram: glioma cells positive for $\mathrm{p}$-Ser10-H3 expression (black=unstained control, red=p-Ser10-H3 (PE staining)). B) Representative results for p-Ser10-H3 and EdU staining of tumor cells isolated from SB gliomas. Tumors were generated by the introduction of the following genetic alterations: NRASG12Voverexpression, p53 and Atrxsilencing for NPA; or NRASG12Voverexpression, p53 and Atrxsilencing, and IDH1R132H overexpression for NPAI (Table 1). Results are shown as the \% of positive cells (left table) or the median fluorescent intensity (MFI) (right table) \pm SD, for each staining. NPAl tumors are less aggressive than NPA tumors and cells show different cell cycle characteristics.

Table 1. Plasmid combinations to generate Sleeping beauty-based gliomas in mouse. As described in the text, oneday-old mouse pups are injected with a plasmid combination to introduce different generic alterations into the subventricular zone brain cells. The specific genetic background generated in these cells will define the aggressiveness of the tumor developed and the median survival of tumor bearing mice, measured as days post injection (DPI). 
